\title{
Ada Dewes
}

\section{De laberintos y lenguajes}

Ensayo

En un primer acercamiento, restableciendo la ingenuidad de la mirada, de esta mirada conducida...

\section{$*$}

En un primer acercamiento un laberinto es un muro.

Muro de piedras o de setos inpenetrables o de una línea que se hace respetar. Lo primero es una división, una diferenciación que, como tal, por sí sola, fundamenta todo espacio. Y esta condición banal de lo diferente, de lo articulado, es igualmente el requisito para que pueda haber sentido, la misma que incita la significación.

El muro del laberinto aisla un mundo en el mundo.

Finalmente cóncavo, últimamente englobante, separa to de adentro de lo de afuera; enconchado, delimitante, instaura la autonomía de lo encerrado, su independencia del entorno.

Así son definịdos los lenguajes: como conjuntos significantes de una organización interna autónoma. Así son pensables los laberintos: como lenguajes.

El laberinto es contenido; el mundo contiene al laberinto como un mundo de lo interior. (Esta primera categoría espacial que diferencia lo interior de lo exterior parece ser una de las primeras categorías semánticas que el hombre aprende a manejar en el lenguaje, tal vez porque es la primera categoría espacial que articula su vida.) 
En un primer acercamiento un laberinto es un muro. Y si esta proposición produce un malestar, no es porque sea falsa, ni siquiera insuficiente, sino porque es legítimamente esto y también aquello: en un primer acercamiento un laberinto es una figura compleja de cimientos. Esta visión inmediatamente evocada es, literalmente, esto: una visión. Desde arriba.

El laberinto pertenece a estas arquitecturas que inducen la posición de sus observadores, sin que éstos perciban que el objeto los localiza en el lugar desde donde lo contemplan. EI laberinto ubica al sujeto construyendo un eje vertical, y lo ubica arriba.

\section{*}

Es decir que el laberinto, él mismo, define su lugar como /interior/ y /abajo/. Sabemos que esta posición no es inocente en nuestra tradición cultural.

(Los expertos se preguntan por qué las fuentes no se pronuncian acerca del techo de los laberintos, por qué presuponen con tal obviedad silenciosa su apertura: ;hay que ser experto para que esta pregunta pueda darse!)

Es entonces así: los laberintos son abiertos hacia arriba, permeados en el eje vertical; ellos son cerrados en el eje horizontal por muros - capas de muros - excepto una única entrada. Este principio es tan imperativo que los muros se convierten en líneas, desde arriba, mientras que, desde abajo, las líneas (de un laberinto dibujado en el suelo) se convierten en muros infranqueables.

Una arquitectura, construida en el sentido de la palabra, pensada, elaborada y edificada por el hombre, invierte entonces, ubica, construye y significa al hombre. La localizacion (este valor de la posición tan considerado por la semiotica reciente) suscita al sentido, y si hubo un malestar, si hubo dos proposiciones, dos acercamientos igualmente válidos, es porque el laberinto crea dos sujetos diferentemente ubicados (o un sujeto esquizofrénico). 
Un sujeto entra al laberinto y un sujeto lo mira; un sujeto recorre y un sujeto observa; un sujeto hace y un sujeto juzga; un sujeto es el héroe y el otro el destinador. El laberinto comienza a Greimas parecerse a los cuentos -una estructura espacial semeja una estructura narrativa.

El recorrer un laberinto implica un desplazamiento continuo que comienza por la entrada única y avanza hacia un centro, un algo, un fin, una finalidad; recorrer un laberinto es lo sucesivo por excelencia, el transcurrir del tiempo, la linealización. De la misma manera el lenguaje hablado nos obliga a desplegarnos en el tiempo, a través de comienzos y finales de frases encadenadas, plasmadas sucesivamente en un significante lineal.

La evocación de los cimientos de un laberinto es visión en un sentido inmediato: simultaneidad de lo percibido. $Y$ ésta es una característica de toda lengua visual. La vista no entra por la puerta. La visión registra lo diverso como Gestalt inmediatamente identificable como laberinto, la visión es este registro simultáneo de todos los caminos, esencialmente atemporal, no lineal, paralelo. Lo simultáneo es lo distinto al mismo tiempo, lo simultáneo es opuesto a lo sucesivo.

Es, tal vez, en la medida misma en que los lenguajes visuales suspenden el ticmpo que el espacio se encarga tan marcadamente de su significación.

Historicamente ha habido dos tipos de laberintos tan profundamente distintos que conviene enfocar su sentido a partir de su oposición: aquellos que conducen, a través de un largo camino único, hacia el centro, y aquellos otros, aparecidos milenios más Kern: tarde, que ofrecen caminos optativos, de los cuales Labyrinthe muchos resultan ser callejones sin salida. A la manera de los mismos "jardines del errar" existe, pues, una bifurcación para abordar lo que es y lo que significa el laberinto. 
Antes de que el camino se divida se encuentra, sin embargo, el fenómeno de la metáfora, esta rareza lingüística que no deja de asombrar a los estudiosos del laberinto. La metáfora se adelantó a la figura espacial que la origina. La metáfora de lo laberíntico como lo que hace errar, lo que lleva a callejones sin salida, lo que retoma, involuntariamente, al comienzo, existió cuando los laberintos, como arquitectura, proveían un solo y único camino que conducía al que recorre de la manera más determinista pensable.

Y era, por así decirlo, la metáfora que öriginó, en tiempos relativamente recientes, a la figura arquitectónica: los "jardines del errar".

De algo consta este fenómeno, y probablemente consta del sujeto dividido: si bien el trayecto del camino es unívoco para aquel que lo toma, quien mira se pierde porque ve todo al mismo tiempo: comienzo y final, va y viene, centro y margen. Es como si le costase al hombre asumir el papel de destinador. La confusión es una especie de "Unübersichtlichkeit"; algo parece escapar a la visión, y esto es, justamente, lo procesual.

La mirada, inepta para recorrer por los textos visuales, imita, en balde, al sujeto que camina; a segunda vista (es un decir: ¿cómo se divide la vista, aun prolongada, en anterior y posterior?) la mirada toma los caminos del laberinto, tiende a saltar los muros, se confunde, se apoya, luego, del dedo que, a su vez, agarra un lápiz...

El laberinto, esta figura vista desde arriba, acaba por linealizar la visión, por "verbalizar" el significante visual.

Lo visual se irrita, se eriza.

La metáfora de lo laberíntico, de lo inextricable, inventada sin antecedente arquitectónico por esta visión enervada, se plasma, finalmente, en los jardines de caminos bifurcados, de caminos posibles. Cada cruce de pasillos se presenta como una figura es- 
pacial de la libertad de elección. Pero la libertad de elección solicita un criterio, y el criterio valoriza: la ecuación de las posibilidades, lo aparentemente arbitrario, solamente dura hasta que se topa con pared: el recorrido se convierte en el andar por caminos equivocados o correctos, sin salida o exitosos, malos o buenos. Este laberinto moralizado, moralizante, es el de la optimización, y lo óptimo aparece como el camino más corto, por lo tanto como el camino más recto.

La valorización positiva de la recta, de la más recta posible, parece negar el recorrido mismo, el camino en tanto placer de andar, placer de perderse. ¿O había, al contrario, justamente este aspecto lúdico en un momento histórico dado? ¿O, aún más complicado, no era el juego con el miedo de perderse lo que hizo construir los jardines del errar? ¿Y no es el juego con el miedo un lujo, el mismo que situaba a estos laberintos en los jardines de los castillos?

Si éstos son los laberintos de la modernidad, si la modernidad entiende por "laberinto" generalmente a los jardines de caminos $\begin{array}{ll}\text { Eco: } & \text { por un efecto de identificación en el cual el laberinto } \\ \text { Apostillas } & \text { es el esquema de una manera de pensar. Ensayo y }\end{array}$ error. La teleología de este proceso, la progresión hacia la meta. También el miedo y la prisa, eventualmente, y la libertad de elección.

Como sea que fuese, solamente si se sabe a dónde se quiere llegar existe un camino optimo. Y, de repente, en los laberintos más recientes diseñados para pasar el tiempo, para perderlo, la meta está donde dice "meta". Nada especial la indica, nada espacial, a veces es una salida del laberinto tan simple como la entrada: la meta se escribió, se puso, se impuso. ¿No será esto mismo un callejón sin salida? ¿De estos laberintos o de esta modernidad? ¿O es esta reflexión la que topó con pared? 
$\mathrm{Y}$, de repente, una nueva atención se centra en los laberintos antiguos, en el laberinto propiamente dicho. En ellos, un solo camino lleva a una plaza en medio, y este camino es, justamente, el más largo posible. Es el camino que cubre la totalidad del interior, que obliga a recorrer todos los lugares. Es el camino de entrada y de salida que convierte al centro en callejón. Callejón tal vez no es la palabra adecuada, en la medida en que asocia "sin salida", lo cual, a su vez, asocia que la entrada no es concebida como salida posible. El centro de estos laberintos es lo que obliga al cambio más radical en la orientación del recorrido.

\section{El centro reorienta.}

Nada de errar, nada de tantcar. El laberinto de Creta columpia al recorrido, mece al trayecto de la mirada (hasta que ésta se marea). Como ụn péndulo que, lentamẹnte, llega a pararse, el laberinto antiguo encamina a un movimiento basculante que oscila hacia un pivote. El centro aspira y espira al sujeto que recorre como un pulmón, lo atrae y lo aleja en arcos finalmente más centrados.

Literalmęnte lo centra.

Este movimiento oscilatorio con sus cambios constantes de direccionalidad, esta caminata de revisión exhaustiva del interior, ha sido, según conjeturas, un baile. Una cadena de bailarines, poKern: siblemente unidos por una cuerda (un hilo), dio origen Labyrinthé a una arquitectura coreográfica: al laberinto como escritura de un baile. (Una etimología seductora pero incierta conduce desde chorós, "baile", ronda, a "Iugar de baile cercado", a gher-, jart, "cercar", a jardin.)

Si hoy los muros condicionan el camino, esta forma hueca llamada negativa, históricamente, aceptando la hipótesis de la escri- 
tura de un baile, es entonces el camino, el caminar, que ha condicionado los muros, forma positiva, las líneas divisorias, el laberinto como tal, como construcción, çomo arquitectura, como jardín, como dibujo. Lo intuimos: esta construcción significa a par-. tir del vacío que encierra, vive a partir del hueco que enmarca, es el hilo invisible de Ariadna, el espacio dejado en blanco, la esencia de lo laberíntico (¿no deberíamos repensar asf nuestra arquitectura, nuestra grafica?).

El laberinto no escribe la huella del movimiento, no dibuja la línea que guía, sino la omite. Y el vacío es, en principio, una ausencia de los flujos de lo vivido, a la vez infinitamente revivible (un vacío se puede llenar, algo lleno ya está ocupado). Las delimitaciones se han quedado como la cáscara estática de lo dinámico, justamente de los recorridos efectuados, de las cadenas de bailarines de un pasado mítico. Es como si un movimiento hubiera petrificado su exterior, tal como los ríos van dejando los escombros de lo que se llevaron, tal como la capa de sal que ciertos lagos sientan en sus orillas. Desaparecido lo blando, lo vivo, lo que existe en y por el tiempo, según las modalidades del tiempo, queda el laberinto como lo duradero que imita a lo pasajero. Queda el laberinto como un espacio de lo temporál.

$*$

Una última reflexión desvía antes de llegar al centro, sin duda una reflexion ya muy concentrada: el laberinto parece ser de esas arquitecturas apriorísticas cuyo espacio condiciona la significacion. No es que represente ciertos pensamientos, sino los causa y

Petitôt

encauza. El laberinto hace reflexionar acerca de lo que se entiende, en semántica, por contenido formal: aquel contenido original de un pensamiento o concepto que depende exclusivamente de su localización; aquella significación embrional que es el valor de una posición relativa en el espacio. El lạberinto parece ser uno de los espacios arquetípicos de lo cognoscitivo. 
Especie de "física del sentido", el espacio del laberinto no. seDerrida: ría estructurado, sino estructurante; no sería un espacio Domus 671 pensado, sino una espacialización del pensamiento.

Plasmando la estructura profunda de las epistemes sucesivas que la engendraron y modificaron, esta arquitectura anticipa su propia significación de manera tautológica, genera lo que retorna para interpretarla: esta arquitectura es una de las arquitecturas de la significación.

El laberinto: un /interior/ que se ubica /abajo/.

El movimiento oscilatorio hacia el centro es un movimiento descendente, por todo el interior, hacia lo profundo (el laberinto: ¡símbolo de los mineros!). ¿Qué se encuentra entonces en el centro? Ciertamente la muerte. Ciertamente lo que cada quien ha llevado hasta allá. Algo muere en este baile de iniciación para renacer difcrente, radicalmente reorientado, regenerado.

Algo nace. Algo cambia de sentido.

El recorrido más largo posible por el interior, por todo el interior, de con-centración y profundización, termina en el centro y recomienza hacia afuera. Extrañamente es esto mismo lo que se enfrenta en el centro, como Teseo confronta al Minotauro: una reorientación radical.

Estamos acostumbrados a pensar que todo tiene su principio y su fin, y entre ambos puntos una línea, un proceso, una cronología. Estamos acostumbrados a pensar así. Y esta línea es la más corta posible, la más recta posible, aquella línea optima que, sin errar, lleva a la meta en los laberintos modernos.

Aquí, en el laberinto de Creta, hay una línea y un punto y una línea (línea la más larga pósible, la más curva posible): fin y comienzo se tocan, en este orden, en el centro del proceso. Y no es una cuestión de renacimiento (además es una cuestión de renaci- 
miento), sino de un acercamiento de contrarios, de la cohabitación de las oposiciones, de su encuentro en un mismo lugar. Lo que se enfrenta como situacion conflictiva e inevitable es, literalmente, el cambio de sentido en medio de un proceso.

¿Cuál sentido? Parece incierto y secundario enunciar el motivo de este recorrido descendente y centrado en términos de un contenido, de una significación determinada. Es como con las estatuas arqueológicas imaginadas por cierta literatura, cuyo significado se revela al imitar su gesto: lo más acertado para constituir esta significación, para reconstruir el sentido perdido, es, tal vez, el recorrer, el volver a recorrer el laberinto. 